\title{
Reseña de Libros
}

\section{Povera per i poveri. La missione della Chiesa.}

Por Juan Chopin.

Título: Povera per i poveri. La missione della Chiesa.

Autor: MÜLLER, Gerhard.

Número de páginas: 310.

Editorial: Libreria Editrice Vaticana.

ISBN: 978-88-209-9276-7.

El autor de este libro es Gerhard Ludwig Müller. Fue ordenado sacerdote por la diócesis de Maguncia (Alemania) el 11 de febrero de 1978. En 1986 fue llamado para asumir la cátedra de teología dogmática en la Universidad Ludwig Maximilian de Múnich. Fue ordenado obispo el 24 de noviembre de 2002 y ejerció su episcopado por diez años en Ratisbona. El 2 de julio de 2012, Benedicto XVI lo nominó prefecto de la Congregación para la Doctrina de la Fe y ha sido confirmado en ese cargo por el Papa Francisco, además de haber sido constituido cardenal durante el consistorio del 22 de febrero del año 2014. Por encargo de Benedicto XVI, Gerhard Müller es el encargado de dar seguimiento a la publicación de la Opera omnia de Joseph Ratzinger.

El título de la obra en la traducción castellana es Pobre para los pobres. La misión de la Iglesia. La expresión «pobre para los pobres» es una frase que recuerda el magisterio del Papa Juan XXIII, retomada por el Papa Francisco al inicio de su pontificado y en sus escritos, por ejemplo en la Exhortación Apostólica Evangelii Gaudium, n. 198.

La edición de la obra, a cargo de Pierluca Azzaro, consta de un prefacio del Papa Francisco y tres partes. En el prefacio, Francisco utiliza un tono prudente respecto al reconocimiento de la teología de la liberación, sin embargo se mantiene coherente en su condena de la idolatría y consiguiente divinización del dinero: «el dinero y el poder económico, de hecho, pueden ser un recurso que aleja al hombre del hombre, confinándolo en un horizonte egocéntrico y egoísta» (Prefacio, pág. 6). 
En la primera parte, titulada La misión liberadora de la Iglesia, G. Müller presenta el sentido de su escrito. Refiere su experiencia entre los pobres de Perú y su amistad con representantes de la teología de la liberación, en particular con Gustavo Gutiérrez, del cual afirma que para él «la Iglesia pobre para los pobres tiene el rostro de Gustavo Gutiérrez» (pág. 15). Menciona también a Josef Sayer y a Diego Irarrázaval vinculados a seminarios sobre teología de la liberación en el contexto peruano. El sentido de la Iglesia aquí se inspira en la narración del samaritano, se asume la fuerza histórica de los pobres ( $G$. Gutiérrez) y se entiende como Iglesia para los otros, en la línea de la teología bonhoefferiana, en la que la historia es el escenario del ejercicio de la libertad. También hay un intento de distinguir entre los presupuestos de la teología de la liberación y los principios marxistas y el ejercicio del comunismo. El autor busca vincular la teología de la liberación con la Doctrina Social del magisterio pontificio oficial. Por supuesto, se trata de minimizar el impacto que en su momento tuvieron las dos instrucciones contra la teología de la liberación, es decir, Libertatis nuntius (1984) y Libertatis conscientia (1986), firmadas en su momento por el entonces prefecto para la Congregación de la Fe, Joseph Ratzinger.

La segunda parte, trata acerca de la misión evangelizadora de la Iglesia, pero más que sistematizar el tema de la misión, en cuanto actividad esencial de la Iglesia, propone el sistema de correlaciones que, en un contexto eclesial, se dan entre la fe, la esperanza y la caridad. En la concepción de G. Müller, la fe no está desvinculada de la realidad del mundo, que es visto como «lugar de epifanía» (pág. 96) y la voluntad del hombre como «lugar de revelación de los significados» (Ibíd.). En la línea de la teología de H.U. von Balthasar, la paradoja de lo eterno en el fragmento, posibilita el surgimiento de la fe, así la fe «reconoce la realidad del mundo como un signo, como un fenómeno que remite a una profundidad a la cual está anclado y de la cual depende en su raíz» (pág. 98). Esta fe se hace operativa en la caridad (fides quae per caritatem operatur) y adquiere una forma escatológica en la esperanza (fides, caritate et spe formata). Para salir al paso de la crisis antropológica que vive el hombre contemporáneo, se propone una vivencia de la fe que supone una necesaria dimensión eclesial (cfr. pág. 118), vista como mundus reconciliatus (San Agustín) y como mundus reconciliams mundum (Pablo VI) (cfr. pág. 150). De modo que la fe en perspectiva eclesial supone una doble tensión: la de descubrir que Dios ha reconciliado consigo al humano que vive en la Iglesia y la tensión a reconocer esa reconciliación como capacitación para que reconozcamos a las personas que viven a nuestro lado (cfr. pág. 151). La recomendación es de poner en práctica los mecanismos de participación que suponen tanto el sensus fidei, 
como el sensus fidelium in Ecclesia, es decir, el sentido de la fe y el sentido de los fieles en la Iglesia (cfr. pág. 165).

En la tercera parte -De América Latina a la Iglesia universal- contiene dos artículos de Gustavo Gutiérrez y uno de Josef Sayer. El primer artículo de G. Gutiérrez trata acerca de la opción preferencial por los pobres en el documento de Aparecida y el segundo presenta la espiritualidad del evento conciliar. El artículo de J. Sayer se refiere a la pobreza como desafío para la fe. Mientras G. Gutiérrez se mantiene en las líneas que caracterizan su teología al leer tanto Aparecida como el Concilio Vaticano II, J. Sayer, en cambio, pone de manifiesto cómo el contexto de pobreza ha permitido construir la amistad entre G. Gutiérrez y G. Müller.

Para un salvadoreño y para la espiritualidad latinoamericana en general, llama la atención lo que dice J. Sayer; en primer lugar, resalta el trabajo que desde tiempos de Mons. Rivera Damas y Mons. Romero realiza la oficina de Tutela Legal a favor de los perseguidos (cfr. pp. 297-298) y hace una afirmación de mucho interés acerca del conocimiento que G. Müller tiene sobre el caso Romero:

«En el momento en el que Müller, como Prefecto de la Congregación para la Doctrina de la Fe, se implica en el proceso de beatificación de Oscar Romero, se puede basar en el estudio intenso de los escritos y las homilías de Romero, como también en el conocimiento del contexto social y político en que el arzobispo Oscar Romero ha trabajado y vivido» (pág. 299).

Como valoración final, llama la atención el interés que el actual prefecto para la Doctrina de la Fe pone en la teología de la liberación, en el sentido de recuperar una corriente teológica que ha sido relegada e incluso combatida.

Sobre todo es revelador y, en el mejor de los casos, esperanzador que en este interés tomen parte el Papa Francisco, Gerhard Ludwig Müller, prefecto para la Doctrina de la Fe y Gustavo Gutiérrez, máximo representante de la teología de la liberación. ¿Cuál será el resultado de esta conjunción? La historia nos lo dirá. 